\title{
EL PROGRESO SOCIAL DE LOS FERNÁNDEZ DE HEREDIA HASTA ALCANZAR EL CONDADO DE ARANDA. UN MODELO PROGRAMÁTICO DE ASCENSO NOBILIARIO ARAGONÉS (SIGLOS XIV-XVII)'
}

\author{
THE SOCIAL PROGRESS OF THE FERNÁNDEZ DE \\ HEREDIA FAMILY UNTIL OBTAINING THE COUNTY OF \\ ARANDA. A PROGRAMMATIC MODEL OF ASCENT IN \\ THE ARAGONESE NOBILITY (14TH - 17TH CENTURIES)
}

\author{
Carmen Corona Marzol \\ Universitat Jaume I
}

\section{RESUMEN}

Es de actual interés el proceso histórico de consolidación de la nobleza desde sus orígenes medievales hasta la tardía edad moderna. El núcleo de este estudio es el linaje de los Fernández de Heredia, familia de la nobleza media aragonesa, que alcanzó un notable desarrollo con el paso del tiempo hasta formar parte de una de las grandes Casas de Aragón y de la monarquía. El estudio analiza las sucesivas generaciones, el proceso de constitución y consolidación señorial, así como las estrategias matrimoniales y el enlace con otras familias de especial interés para el futuro del progreso colectivo. Este proceso sirve como muestra de uno de los modelos sociales que explican el comportamiento de la nobleza en vías del deseado ascenso social, utilizando para ello los mecanismos propios del Antiguo Régimen.

Palavbras clave: nobleza, nobleza aragonesa, mayorazgo y vínculo, familia de los Fernández Heredia, condado de Aranda, linaje de los Díez de Aux, justicia de Jaca y de las montañas de Aragón, gobernadores de Aragón, virreyes de Aragón, Juan José de Austria.

\begin{abstract}
The historical process of the consolidation of nobility from its medieval origins to the late Modern Era is currently a matter of interest. The core of this study is the lineage of the Fernández de Heredia family, a family of the Aragonese middle nobility which made remarkable progress until it became one of the main Houses of Aragon and part of the monarchy. The study analyses the successive generations, the process of noble constitution and consolidation, as well as the marriage strategies and liaison with other families of special interest for future collective progress. This process serves as an example of one of the social models which explains the behaviour of the ascending nobility, using the tools of the Ancient Regime.
\end{abstract}

Keywords: nobility, Aragonese nobility, mayorazgo and vínculo, the Fernández Heredia family, County of Aranda, Díez de Aux lineage, Justice of Jaca and of the Aragon mountains, Aragon Governors, Aragon Viceroys, Juan José de Austria. 


\section{INTRODUCCIÓN}

El estudio pormenorizado de familias concretas constituye uno de los métodos de trabajo más seguro y eficaces para demostrar los caminos de consolidación de la nobleza en el Antiguo Régimen. Los casos individuales nos adentran en la dinámica, las estrategias privadas y conjuntas de estos grupos, y los mecanismos de promoción, unas veces accidentales, y otras, que prosiguen las tendencias y los mecanismos colectivos de la evolución social del grupo a lo largo de la Edad Moderna.

Estas páginas intentan penetrar en los orígenes familiares, vida personal y circunstancias del linaje aragonés de los Fernández Heredia, familia de la nobleza media aragonesa, cuyo destino les llevó con el tiempo a poseer las propiedades, títulos y oropeles del condado de Aranda a mediados del siglo XVII.

\section{El CAMINO RECORRIDO POR SEIS GeNeRACIONES. LA CONSTITUCIÓN Y EVOLU- CIÓN DE VARIOS SEÑoRÍOS DE VASALLOS}

\subsection{El antiguo tronco familiar. Los Díez de Aux}

Las historias sobre el Reino de Aragón recogen habitualmente una información parcial sobre el linaje de los Díez de Aux. Los datos generales ahondan en su antigüedad, referida al año 1250 cuando se constata la existencia de don Juan Díez de Aux en Aragón. La familia era oriunda de Bielsa, pero con el tiempo aparecen afincados en varias poblaciones importantes de Aragón, entre ellas Daroca, Calatayud, Luceni y Alfocea.

Entre los miembros de esta familia infanzona aragonesa ha tenido en la memoria colectiva especial relevancia Martín Díez de Aux, vecino de Daroca, e hijo de Juan Díez de Aux y su esposa Martina. Ejerció el cargo de justicia de la Comunidad de Daroca en 1416 y en 1421. Luego ocupó el cargo de lugarteniente de Baile, y Baile General del Reino. En 1429 fue

1 Este trabajo se está realizando dentro del proyecto de investigación: De pequeños hidalgos a nobles titulados. Riquezas, poder y redes clientelares de la nobleza mediterránea (PI. 1A2014-13). Investigador principal: Carmen Corona. Universitat Jaume I (2015-2017). 
nombrado alcaide de Daroca. La culminación de su carrera la constituyó el ser nombrado justicia de Aragón con carácter vitalicio.

Las Cortes de Teruel de 1428 le encomendaron la compilación de una colección oficial de las Observancias del Reino. Don Martín Díez de Aux con sus colaboradores seleccionaron los fueros y usos, que todavía se consideraban en vigencia, y crearon una compilación de observancias que se añadieron a las ediciones impresas de los Fueros de Aragón. El texto legal fue aprobado en 1437 por las Cortes de Alcañiz.

Don Martín Díez de Aux se casó en primeras nupcias con Doña Isabel Cerdán, con la que tuvo a Martín, camarero del rey Alfonso y señor de Alfocea. En segundas nupcias se emparentó con Doña María Jiménez de Liñan, con la que tuvo 3 hijas². $^{2}$.

\subsection{Ad futura rei memoriam. La probatoria de ilustre linaje $y$ el cruce de los apellidos}

Como parte sustancial de la construcción histórica de un linaje era necesaria la existencia de un ascendiente glorioso, que dignificase la estirpe y diese por seguro la calidad nobiliaria de la familia, constatándolo para el conocimiento público, cuando el proceso de ennoblecimiento así lo requería. Las formas fueron variadas y distintas según el paso de los siglos, pero casi todas confluyeron en buscar el origen en tiempos antiguos y heroicos, generalmente en épocas de conquista y hazañas militares. De esta forma el linaje adquiría la connotación de inmemorial. En la familia de los Fernández de Heredia el linaje histórico fue el de los Díez de Aux.

El procedimiento de esclarecimiento de la nobleza familiar se desarrolló en el siglo XV, en época de don Martín Díez de Aux, tras su desposorio con doña Juana Fernández de Heredia. Utilizaron para ello la vía de la probatoria judicial municipal, procedimiento usual que otorgaba a las justicias ordinarias de los municipios la facultad de esclarecer y ratificar el pasado ilustre familiar mediante un proceso público de comparecencia de testigos y verificaciones.

La base de esta probatoria se basaba en la constatación de la memoria colectiva popular sobre la calidad del linaje y la posesión de propiedades de la familia desde tiempos remotos. El método de la ratificación de esta

2 GIMÉNEZ SOLER, A. (1899): "El Justicia de Aragón, Martín Díez de Aux" (http://www.derechoaragones.es/i18n/catalogo_imagenes/grupo.cmd?path=101364). Revista de archivos, bibliotecas y museos, tomo 3, Madrid, pp. 385-391. Véase el árbol genealógico 1, para mayor profundización. 
forma de imaginario colectivo se basaba en la declaración de varios testigos ancianos que verificaban, de forma verbal y presencial, que habían oído decir a sus antepasados, de generación en generación y a través de los siglos, la calidad de la nobleza familiar objeto de la probanza. El justicia de la localidad bajo la fórmula consuetudinaria ad futuram rei memoriam mandaba llamar mediante citación y requerimiento la comparecencia de las personas escogidas, quienes "en virtud de juramento" declaraban y decían lo que sabían ellos, sus antecesores más directos, sus antepasados y la "voz común" del lugar, siguiendo las fórmulas de un cuestionario establecido.

En el proceso de los Díez de Aux se les instaba a dar las certezas correspondientes de tres cuestiones concretas sobre la prueba de nobleza. La primera era su lugar de procedencia y establecimiento en el municipio sede del proceso, en este caso era la ciudad de Daroca, aunque los Díez de Aux residían en Castejón, aldea próxima a ella dónde radicaban sus posesiones territoriales. Para ello dieron constancia de que tanto los antecesores familiares como los presentes habían permanecido alli desde hacía 400 años de antigüedad. Uno de sus más próximos antepasados, don Juan Díez de Aux, abuelo de don Martín, quien había solicitado la probatoria, era recordado unánimemente, y tenidos como señores antiguos de la población de Bielsa, aunque sus descendientes habían permanecido siempre en Castejón. La calidad de caballeros fue pronto despejada por sus orígenes y por el hecho comprobado de que, como signo palpable de su distinción, jamás pagaron gravamen alguno en la localidad, ni habían sido juzgados por los tribunales ordinarios en ningún proceso, como correspondía a su calidad social. Este hecho era público y notorio en la localidad, ya que en el momento, la familia seguía exenta de efectuar pagos ordinarios al ser considerados como caballeros.

Además, siguiendo el árbol genealógico familiar, quedaba acrisolada en la memoria colectiva que los Díez de Aux procedían de la Casa real de Francia por descendencia directa del rey Enrique I por sucesión, en línea recta, de un hijo natural del primogénito, el infante Hugo. Así desde entonces era conocido "de fama y voz común" que don Hugo Díez de Aux había dado lugar al linaje establecido en tierras aragonesas ${ }^{3}$.

De esta forma los Díez de Aux siempre habían sido considerados nobles de Aragón, prueba de ello era su asistencia a celebraciones de la realeza en el reino en diversas ocasiones, tales como cuando la princesa Juana fue jurada como sucesora al trono en 1502 en Aragón. 
La tercera parte versaba sobre la propiedad de la tierra, cuestión de vital importancia en el momento. Según aseguraron todos los testigos presentados, el patrimonio territorial, que entonces conservaba el linaje, fue otorgado por los reyes en tiempos de la conquista. Don Hugo Díez de Aux, señor de Bielsa, ayudó al rey don Alfonso I en sus campañas y a cambio le otorgó bienes y posesiones que recibió en donación, y que todavía seguían existiendo en la ciudad de Daroca, y en Castejón. La sucesión había continuado trasmitiéndose por vía directa de varón. La constatación de este hecho histórico quedó plasmado en el escudo de armas y en la heráldica de la villa, luego ciudad en 1366.

Todo ello pretendía no solo colaborar a consolidar una conciencia de linaje y de apellido, sino crear una identidad, un símbolo y un lenguaje heráldico, con el que identificar y recordar su ilustre pasado, con la finalidad de avanzar en la vía del prestigio y la constatación de una inmemorial preeminencia social.

La familia de los Fernández Heredia optó, como otros muchas familias nobiliarias, en utilizar con el paso del tiempo el apellido $u$ apellidos del creador del vínculo nobiliario base del patrimonio alcanzado. Tras unas

Árbol 1: de los Díez de Aux y Fernández de Heredia

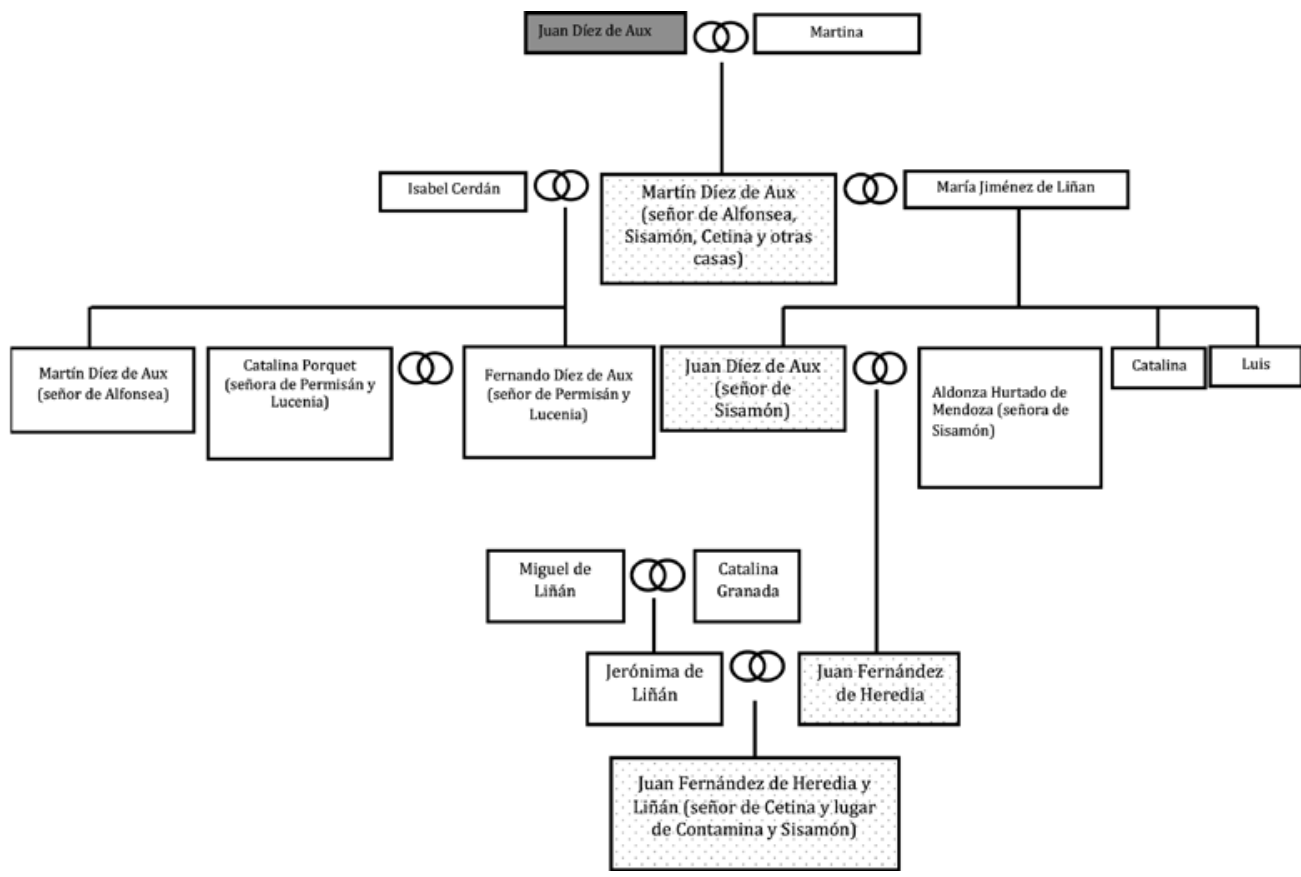


cuantas generaciones se optó por el abandono de Díez de Aux y la utilización del patronímico de los Fernández de Heredia, debido a los enlaces matrimoniales y posiblemente, como una forma de consolidación del apellido que vinculase más directamente sus raíces con el reino de Aragón, olvidando la gloriosa procedencia francesa del linaje Todo ello favorecería con el tiempo la promoción en puestos de servicio institucional en el reino, de una estirpe de raigambre histórica indudablemente aragonesa.

\subsection{La constitución del linaje de los Fernández de Heredia}

Comenzamos a esclarecer el tronco familiar desde don Luis Díez de Aux, para no alargarnos excesivamente en el tiempo, nos centramos en la época que queremos reseñar y entrelazar con el linaje objeto de estudio.

Don Luis Díez de Aux se desposó con doña Violante Fernández de Heredia, iniciando así el fructuoso linaje que nos ocupa. A partir de este momento se abandona el apellido de los Díez de Aux y se utiliza sin mención alguna el nombre del nuevo linaje de los Fernández Heredia.

Continuó la línea sucesoria su hijo y heredero don Juan Fernández de Heredia, que de su matrimonio con doña Aldonza Hurtado de Mendoza incorporó el señorío de Sisamon, aportado en la dote nupcial por la novia ${ }^{4}$. Su hijo y sucesor, Juan (Díez de Aux) Fernández de Heredia, de su primera nupcia con Jerónima de Liñán, sumó al patrimonio familiar el señorío de $\mathrm{Ce}$ tina $^{5}$. Este señorío fue entregado por don Miguel de Liñan, padre de doña Jerónima, como aportación de dote al nuevo matrimonio. Don Miguel de Liñan se había casado el 10 de marzo de 1509 en Molina de Aragón con doña Catalina de Granada, incorporando a su nueva familia los señoríos de Cetina y Contamina'.

En el matrimonio de Juan Fernández de Heredia con Jerónima de Liñán, este aportó una donación de su madre de 2.000 florines de oro, provenientes de la dote materna, sobre el lugar de Sisamón. Junto a la mencionada cantidad se incluía el dominio señorial de Sisamón con la jurisdicción civil y criminal. Se incorporaron también heredades y cañadas del lugar de Iruecha, una aldea próxima a la villa castellana de Medinaceli. Además de este legado doña Jerónima aportó al matrimonio una cantidad de dinero en moneda que ascendía a 44.000 sueldos. La condición impuesta a don Juan fue la prohibición de poder vender o empeñar el legado, con la

$4 A H P r Z$, Arguillo, caja 2164, leg. 62, exp. 18.

$5 A H P r Z$, Arguillo, caja 2164, leg. 62, exp. 14.

6 AHPrZ, Arguillo, caja 2164, leg. 62, exp. 29. 
condición añadida de tener que traspasarlo al hijo mayor del matrimonio, o en su defecto, a la hija mayor?. Conocemos que el dominio señorial de Sisamón pasó al hijo mayor, Juan, el 18 de septiembre de 1578. Siete años más tarde, en 1585, murió en el señorío familiar de Cetina, que había sido cedido a su vez por su padre, el 18 de febrero de $1557^{8}$.

En las tres generaciones primeras de nuestro estudio esta familia estaba incrementando sus propiedades y asegurando su status social, como señores de vasallos. Pero serán las tres generaciones siguientes las que asentaran definitivamente la posición del linaje en la sociedad aragonesa. En este punto debemos detenernos en el segundo matrimonio de don Juan Fernández de Heredia con doña Juana Palomar, de la que nacerá su hijo don Jerónimo Fernández de Heredia y Palomar, segundón en la transmisión de los legados familiares, pero pieza fundamental en la consolidación social e institucional de los Fernández de Heredia. La importancia de esta segunda fase del ascenso familiar queda constatada en la documentación pertinente con el abandono del primer apellido paterno (Díez de Aux) y la adopción definitiva del de Fernández de Heredia como identidad transmisora de la descendencia posterior.

\subsection{El otro escalón del linaje. La consolidación de las tres generaciones siguientes de los Fernández de Heredia}

Don Jerónimo Fernández de Heredia realizó también un ventajoso enlace matrimonial con doña Ángela de Rueda, cuyas capitulaciones nupciales quedaron pactadas entre finales de febrero y el 1 de marzo de 1579 .

Don Jerónimo llevó como bienes nupciales el término de las Cañadas en Sisamón, y una serie de casas en la misma población a la que se añadieron 14 hanegadas de tierra en el término de Calatayud. Aportaba además 2.500 sueldos jaqueses de renta, con otros 50.000 sueldos de propiedad producto de un censal emitido por los antiguos señores d Sisamón; otros 80.000 sueldos jaqueses que le debía el concejo de la villa de Sisamón y 3.500 sueldos provenientes de una renta anual que le debía de pagar su hermano Juan. Paralelamente la novia Ángela de Rueda aportó como dote varias fincas rústicas y urbanas del término de Épila. Las rentas y censales constituían un importante legado, 6.040 sueldos jaqueses de renta y 123.500 sueldos de propiedades en censales de diferentes poblaciones

\footnotetext{
$7 A H P r Z$, Arguillo, caja 2164, leg. 62, exp. 10.

8 AHPrZ, Arguillo, caja 2164, leg. 62, exp. 19 y AHPrZ, Arguillo, caja 2164, leg. 62, exp. 20.

9 AHPrZ, Arguillo, caja 2119/20.
} 
ÁrBOL 2: de los Fernández de Heredia y sus enlaces matrimoniales

Doña Donosa Fernández de Heredia

(2) don Sancho González de Heredia

Mosén Juan Fernández de Heredia

(6) doña Ysabel de la Cerda

Don Juan Fernández Heredia y la Cerda

(6) doña Violante Garcés de Eusa

Doña Violante Fernández de Heredia (1) don Luis Díez de Aux

Don Juan Fdez. de Heredia $(0$ doña Aldonza Hurtado de Mendoza

Don Juan Díez de Aux Fernández de

Heredia $\odot$ doña Gerónima Liñán

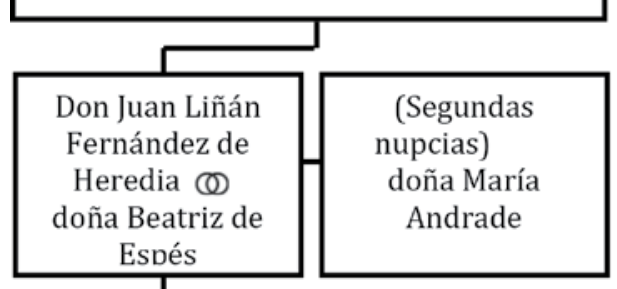

Don Juan Fdez. de

Heredia y Liñán $\varnothing$

doña Esperanza de

Román

Don Alonso Fdez. de

Heredia y Liñán, conde

de Contamina (6)

doña Ysabel Altarriba y

Castro
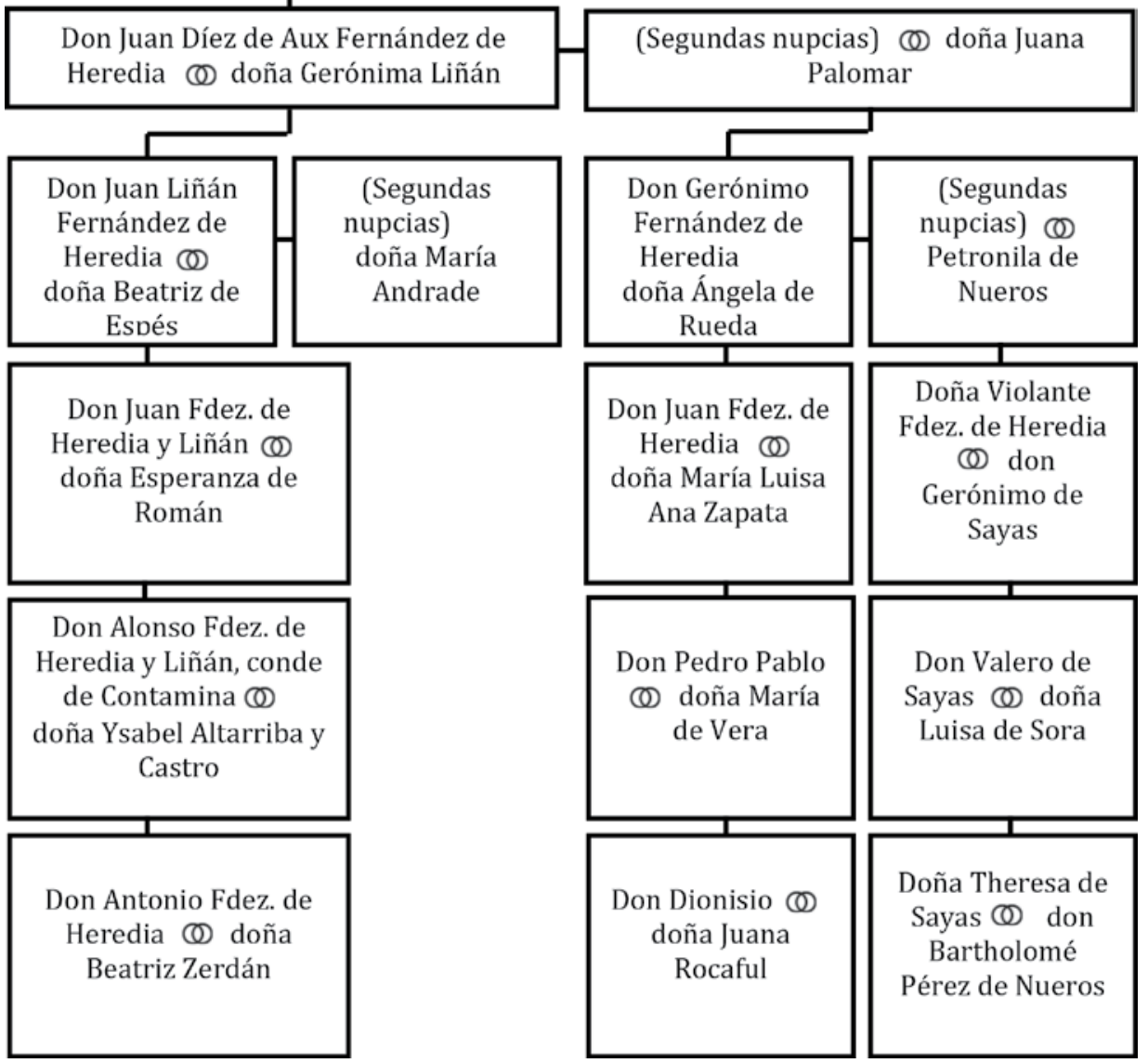
aragonesas (Zaragoza, Cadrete, Villarroya, Ayerbe, Utebo, Mesones de Isuela, Bardallur, Rivas-Ejea de los Caballeros, Fuentes de Jiloca, Tierga, Gallur, Escatrón, Abanto, Mara y Castejón, entre otras). A esto se añadían 30.000 sueldos jaqueses en oro, plata, joyas y otros bienes muebles. Es de destacar la viudedad foral que se concede a don Jerónimo Fernández de Heredia de los bienes de Épila, en los treudos perpetuos de la villa y en 1.000 sueldos de renta de los censales aportados por doña Ángela. Por su parte también ella tenía una viudedad foral en todos los bienes de su marido y en aquellos 1.500 sueldos de renta anual aportados por él.

Doña Ángela de Rueda murió en Huesca el 23 de octubre de 1590. Del matrimonio dejaron un linaje que posteriormente encumbraron a la familia con diversos puestos en el servicio real. Sin embargo, don Jerónimo volvió a casarse en segundas nupcias. El 3 de julio de 1591 se casó con doña María Pérez de Nueros, hija del caballero don Jerónimo Fernández de Heredia y de doña Petronila de Nueros. La capitulación matrimonial se firmó en Zaragoza el 18 de mayo de 1591. Ambos residieron en la villa de Sisamón ${ }^{10}$.

Sucedió en el mayorazgo de don Jerónimo su hijo Juan Fernández de Heredia, que casó con doña Ana Luisa Zapata y Urrea, madre de don Pedro Pablo Fernández de Heredia y Zapata, futuro conde de Aranda.

A pesar de todo lo expuesto en 1603 las rentas obtenidas en cahíces de trigo, cebada y avena de Sisamon, Cetina y el lugar de Contamina producían anualmente 30.583 sueldos y los gastos generales $452.495,4$ sueldos. No es de extrañar las quejas de don Jerónimo Fernández de Heredia cuando escribía al rey manifestándole que los servicios realizados en sus diferentes cargos, le habían supuesto el perder gran parte de su hacienda familiar.

Posiblemente estos datos parciales de que disponemos, acercasen a la familia a proseguir la senda del servicio a la Corona y estudiar con mayor detenimiento los futuros enlaces familiares.

Don Pedro Pablo Fernández de Heredia Zapata y Urrea casó con María Josefa Oriola Olm de Vera, Jover, Claver y Fernández de Hijar y Camargo. Este matrimonio significó el broche de oro para el linaje que nos ocupa, y colmó de honores y patrimonio a los futuros descendientes. Nos interesa indagar algunos datos personales de los padres de la novia, para valorar debidamente la importancia de todo tipo que para el colectivo parenteral significaron estas nupcias. Don Francisco de Vera era caballero del hábito de Calatrava, y su esposa, Josefa, provenía de la familia de los Camargo y Castejón, ambos domiciliados en la ciudad de Zaragoza y pertenecientes 
a la élite urbana. Como padrinos o curadores intervinieron los Condes de Belchite y los de Plasencia.

El novio don Pedro Pablo, aportó un total de 19 campos y heredades de todo tipo de las sucesivas herencias incorporadas al legado familiar, todos ellos en el término de Épila, junto a censos de tierras, censales, y unos cuantos mesones. A ello se añadía la población de Escatrón y porciones de tierras de la Vega de Calatayud.

\subsection{Las diferencias entre los señoríos familiares}

Resulta interesante indagar en el origen y formas de transmisión de los mayorazgos en cada una de las familias objeto de estudio, y comprobar cómo con el tiempo se van entroncando, generando confluencias y cambios en la propiedad de la tierra y su transmisión sucesoria. En el linaje que nos ocupa queremos marcar las diferencias entre los dos señoríos y villas heredadas más importantes, y ver las disposiciones establecidas con el tiempo.

El núcleo fundamental y originario del patrimonio territorial de los Fernández Heredia fue la villa de Sisamón, a la que se añadió la villa de Cetina y el lugar de Contamina. Constituyó el patrimonio más antiguo del linaje y el sustento de la preeminencia social de las primeras generaciones

Este conjunto de bienes, como era habitual en la nobleza, debía trasmitirse íntegro al sucesor con la necesaria prohibición de poder enajenar la parte del patrimonio familiar sujeta al régimen de mayorazgo.

Ya conocemos el valor del vínculo por medio del cual se sujetaba la tierra a una familia a perpetuidad, y esta propiedad de la nobleza quedaba así protegida jurídicamente. En la mayoría de los casos en el proceso de constitución del vínculo, el creador del vínculo establecía el orden de la sucesión familiar, y todas las condiciones que debían cumplir los posibles herederos. De todos es conocido la necesidad de la nobleza de defender sus propiedades, y en concreto la del mayorazgo, para perpetuar su linaje, fuerza económica y preeminencia social.

En la villa y tierras de Sisamón se constituyó un señorío "con todos los derechos y pertenencias, jurisdicción civil y criminal, alto y bajo mero y mixto imperio bienes y pertenencias, pertenecientes al dominio y dominicatura $^{\prime 11}$. En una carta de donación de este señorío por don Juan Fernández de Heredia a su hijo don Juan Fernández de Heredia Liñán, señor de la villa de Cetina y del lugar de Contamina el día 18 de noviembre de 1557, 
podemos apreciar medidas tan comunes como identificativos de la forma de proceder de la nobleza'2

En ella se ratifica la constitución de un mayorazgo de tipo regular con las condiciones específicas para sus herederos.

"Los dichos bienes de la donación de legítimo matrimonio, no sea del todo ciegos ni mudos, ni furioso ni mentecato, ni clérigo ni fraile, ni constituido en ninguna orden sacra, que le impida ser casado, y así en vuestro nieto, bisnieto, y tercero y cuarto descendiente del primogénito para siempre jamás, que no sean ni padezcan impedimentos de ser nombrados y especificados."

El vínculo especificaba que si el primer hijo varón no tuviese hijos varones pasase al segundo, y así, de grado en grado, a los sucesivos descendientes siempre siguiendo la línea de la primogenitura. A falta de hijos varones debían heredar las hijas legítimas, con las condiciones habituales, "ni ciegas, ni mudas, ni monjas ni beatas, ni tengan algún defecto que les impidiese casarse"13.

Como era usual se insistía en la condición de que los bienes constitutivos del mayorazgo no podían ser vendidos ni enajenados, ni puestos a censo ni en enfiteusis ni sujetos al pago de deudas, ni lógicamente desmembrados por capítulos matrimoniales, y los demás requisitos habituales en los vínculos.

La gracia de esta donación consistía en que por las circunstancias concretas de la familia, se le hacía la manda a Juan Fernández de Heredia de que el señorío de Sisamón pasase a su hermano segundo, Jerónimo Fernández de Heredia, hijo de Juana Palomar, segunda esposa de su padre, y así pasase a la sucesión de sus hijos varones y hembras. De hecho heredó el mayorazgo su hijo mayor don Juan Fernández de Heredia y Palomar.

El señorío de Cetina tuvo una trayectoria diferente y un transcurso histórico nada habitual. Procedía en origen de las villas y tierras del realengo aragonés. La historia de su vinculación a la familia de los Fernández de Heredia fue harto complicada en el transcurso de dos siglos, aunque jurídicamente se resolvió con el tiempo, y favorablemente a la familia, constituyendo este señorío otra de las bases de los territorios señoriales vinculados, y del patrimonio territorial con los ingresos económicos correspondientes, que luego comentaremos. 
Fue el rey Juan I de Aragón, quien el 4 de septiembre de 1391, vendió a Juan Fernández de Heredia la villa de Cetina por un valor de 5.500 florines de oro del reino. Acto seguido el nuevo propietario la aseguró mediante carta de gracia con pacto de retroventa para el rey y los habitantes, por el mismo precio, el 22 de septiembre del mismo año.

Por el poder otorgado en la venta Juan Fernández de Heredia tomó posesión de Cetina y su tierra el 18 de octubre siguiente del año de 1391. La trayectoria histórica hizo que la villa y sus propiedades jurisdiccionales experimentasen un angosto camino cuando el rey Martín V el 28 de abril de 1405 por los servicios prestados a su hijo primogénito el rey Martín de Sicilia por Sancho Rodrigo de Liorri, consejero y camarlengo suyo, hizo a este donación de lus Luendi, concediéndole la libre disposición de Cetina y sus tierras, con los derechos dominicales, jurisdicción civil y criminal, mero y mixto imperio, quitando el recurso de apelación al Gobernador y al Justicia de Aragón.

En consecuencia el rey Martín de Sicilia aprobó la donación efectuada a Sancho Rodrigo de Liorri y la ratificó por Privilegio del 10 de octubre de 1405. De este modo Sancho Rodrigo de Liorri, usando la carta de gracia de la donación y confirmación recibió la villa de Cetina con las tierras, y tomó posesión de ella el 17 de enero de 1406. Tras esto vendió la villa a la familia de los Liñán, con sus vasallos, jurisdicciones y términos por el precio de 20.000 florines de oro de Aragón, incluyendo la carta de pago y de luición plenaria, poniendo de fiador a mosén Juan Fernández de Heredia, señor de la villa de Mora. Gonzalo de Liñán, fue después señor del lugar, descendiente y legítimo sucesor de los compradores.

Posteriormente otro proceso se interpuso en el normal funcionamiento de este señorío. El asunto era anterior y consistía en el intento de incorporación de Cetina a la Comunidad de Calatayud atendiendo a un Privilegio real, concedido por el rey Pedro IV en Zaragoza el 28 de abril de 1372. El privilegio incorporaba las diferentes poblaciones circundantes a la Comunidad de Calatayud, pagando esta al real erario por la donación la cifra de 3.500 florines de oro de Aragón. De este hecho resultaba un fideicomiso perpetuo a favor de la Corona, como resultado derivado.

Se cuestionó durante un tiempo si la monarquía tenía derecho al dominio respecto a la villa de Cetina y sus tierras. En el documento Cuaderno de noticias de la egresión de la villa de Cetina quedan referidas y rebatidas ocho importantes matizaciones jurídicas, que según la legislación de la época, aclaran el tortuoso proceso jurisdiccional. Entre ellas vamos sólo a referir las más aclaratorias. La incorporación se hizo a la Comunidad y no a la Corona, por servicios y a beneficio de la Comunidad, como constaba en el comienzo del Privilegio, y como se decía ibi sub conditionibus. En la 
relación de las villas comprendidas en el proceso no figuraba Cetina, lo que daba indicio de que su situación jurídica y patrimonial era diferente a las demás ${ }^{14}$.

Otro argumento importante se refiere al proceso de ajenaciones de la Corona, en los que los reyes dieron a los señores los patrimonios libremente, y ellos los poseyeron en paz y con título legítimo. Así quedó demostrado que el primer acto de posesión señorial fue el de don Juan Fernández de Heredia. Paralelamente constaba que la incorporación de la Comunidad se realizó en el año de 1432, y los predecesores propietarios de Cetina, la fueron poseyendo desde hacía 193 años, y que, durante este tiempo, se realizó la constitución del señorío y la realización del vínculo. Por último el argumento contundente era la inexistencia del fuero Conservatione patrimonii, acordado en 1461, que marcaba los límites de los reyes en los procesos de ajenación de bienes.

En la historia que nos ocupa, este Juan Fernández de Heredia fue "el mayor señor de la Casa", como refieren los documentos de la época, y casó con Isabel de la Cerda, hija del conde de Medinaceli. Fue además señor de Zorita y de Foyos, y hermano de Blasco Fernández de Heredia, a su vez señor de Jaulín. Para comprender el peso específico que tan tempranamente tenían ya en Aragón los Fernández de Heredia, hay que conocer el incremento patrimonial del que disponían ya los otros miembros colaterales familiares, siendo solo por entonces señores de vasallos.

Esta tendencia la podemos encontrar en las antiguas propiedades del linaje que fueron vendidas por Alfonso $V$ en 1430 por 13.000 florines de Aragón, y fueron recompradas por Juan Ximénez Cerdán, miembro de un grupo social colateral emparentado con los Fernández de Heredia. En este caso concreto fue Martín Díez de Aux, entonces señor de Alfocea y de otros lugares como el Castelar, quien vendió a la Corona uno de sus patrimonios heredados, que con el tiempo retornaría al núcleo familiar, cuyo estudio nos ocupa. Es necesario por tanto remontarse a los orígenes del linaje para poder establecer con concreción cuáles fueron las verdaderas propiedades familiares que dieron origen a los señoríos y tierras colaterales por un lado, y por otro, las ventas que la Corona dio a los señores de vasallos con las que ampliaron sus patrimonios. 


\subsection{La entrada al servicio del rey y la promoción institucio- nal de sus miembros}

Paralelamente al incremento económico de la familia y a su instauración en el seno de la nobleza aragonesa, los Fernández Heredia se introdujeron en otro proceso de indudable interés, tanto para el ascenso de la estirpe como para el futuro acrisolamiento de sus descendientes. La entrada al servicio de la monarquía vinculó definitivamente su status en la sociedad aragonesa, así como la adopción del hábito de Órdenes Militares, que en este caso, se eligió la Orden de caballería de Santiago.

Don Jerónimo Fernández de Heredia comenzó su carrera al servicio de la monarquía de los Austrias en el reino ocupando el primer cargo de Justicia de Jaca y de las montañas de Aragón. Nombrado por privilegio real el 3 de agosto de $1586^{15}$, desempeñó su empleo hasta el 30 de agosto de $1601^{16}$. En 1585 inauguraría la primera andadura de este nuevo cargo real, que con el paso de los años irían desempeñando sus sucesores junto a otra familia aragonesa, vinculada colateralmente por sus enlaces matrimoniales con los Pérez de Zayas ${ }^{17}$.

Esta magistratura tenía un interés especial por sus cometidos jurisdiccionales y su posición institucional en el ordenamiento foral autónomo aragonés. Como justicia de Jaca y de las montañas ejercía las funciones de impartición de justicia en los casos específicos estipulados por los Fueros y Observancias de Aragón. Los procesos se llevaban a cabo en las villas y ciudades, en las que debían concurrir según sus cometidos, entre los que se encontraban el sostenimiento del orden público. Para el ejercicio de sus funciones disponía de un grupo de soldados, que le servían de guarnición y le acompañaban y ayudaban en el ejercicio de la mencionada actividad ${ }^{18}$.

El marco jurisdiccional del cargo de Justicia de Jaca y de las montañas recogía una serie de poblaciones de la franja del Pirineo aragonés, abar-

15 GÓMEZ DE VALENZUELA, M. (2006a): Diplomatario tensino (1315-1700). Real Sociedad Económica de Amigos del País, Zaragoza, pp. 335 y 339-344.

16 GASCÓN PÉREZ, J. (2001): La rebelión aragonesa de 1591 [Recurso electrónico]. Universidad de Zaragoza, Zaragoza, p. 1320.

17 GÓMEZ ZORRAQUINO, J. I. (2008): "El justicia de las montañas de Aragón (1585-1672): La institución y sus oficiales". Revista de Historia Moderna, Anales de la Universidad de Alicante, 26, Marcial Pons, Madrid, pp. 61-89.

18 SAVALL Y DRONDA, P. y PENÉN DEBESA, S. (1991): Fueros, Observancias y Actos de Corte del Reino de Aragón (ed. facs. con estudio preliminar de Jesús Delgado Echeverría), tomo I. El Justicia de Aragón e lbercaja, Zaragoza, pp. 421-455. 
cando desde las ciudades más importantes y representativas de la zona, como determinados valles con los núcleos rurales de mayor relieve. Comenzando por Jaca eran de su espacio territorial Berdún, Bielsa, Biescas, Los Valles de Tena, el de Basa y Serrablo, el Valle de Tena, el Valle de Aragües del Puerto, San Esteban de Litera, Boltaña, Adahuesca, el Valle de Aísa, el de Hecho, Salvatierra y Gistau ${ }^{19}$. Bajo su jurisdicción se incluían también el desempeño de las funciones de alcaide de los castillos de Candanchú y Ruesta ${ }^{20}$.

La importancia de este oficio real radicaba esencialmente en ser un servidor de la jurisdicción real en Aragón, y como tal pertenecer a la élite funcionarial de los servidores de la monarquía. Su cometido consistía esencialmente en sustituir a las justicias ordinarias, atendiendo y reforzando la jurisdicción criminal, interviniendo en los procesos y ejecutando las sentencias habidas en los concejos aragoneses. Los asuntos judiciales de su cargo recaían preferentemente en materias de hurto y asaltos en los caminos, asesinatos, crímenes y homicidios, así como asuntos de delincuencia común y bandolerismo ${ }^{21}$. Todas estas funciones quedaron reservadas en los fueros aragoneses a la monarquía. Por tanto al depender directamente del monarca su área de acción recaía sobre las poblaciones o universidades de realengo, y carecía de jurisdicción alguna entre los diferentes tipos de señoríos.

Esta magistratura de origen real establecería en la primera generación de los Fernández de Heredia que ostentó el cargo una serie de ventajas de índole social y de prestigio, dando paso a una consolidación del status familiar y del apellido, iniciándose el camino con don Jerónimo Fernández de Heredia, quien fue nombrado posteriormente regente de la General gobernación de Aragón.

La fuerza inherente de este primer encargo real se veía reforzada por la propia naturaleza del cargo de Justicia de Jaca y de las montañas en el engranaje interno de sistema estatutario foral aragonés. Esta magistratura, perfectamente delimitada en el ordenamiento jurídico propio, le concedía atribuciones en defensa de los derechos históricos aragoneses, lo cual le

19 AHPrZ, Arguillo, caja 2187, leg. 1-15.

20 DESPORTES BIELSA, P. (1998): "El justicia de las montañas". Serrablo, 108, Amigos del Serrablo, pp. 21-24.

21 COLÁS LATORRE, G. y SALAS AUSÉNS, J. A. (1982): Aragón en el siglo XVI: alteraciones sociales y conflictos políticos. Universidad de Zaragoza, Zaragoza, pp. 370 y 396. 
situaba en un lugar intermedio en el peso institucional local. El cargo colocaba al magistrado en cuestión entre el servicio del rey y el de los aragoneses, en un equilibrio instrumental, que revalorizaba su peso en ambos espacios de poder, como servidor real y defensor de los acuerdos tomados en Cortes en el seno del pactismo aragonés. Según los propios fueros este magistrado debía ser natural del reino y estar domiciliado en Aragón, cuyo nombramiento procedía de la monarquía, previa consulta del Consejo Supremo de Aragón, que establecía el orden de los candidatos y su calidad en el desempeño del cargo.

Todo ello bien utilizado socialmente y con un desempeño del cargo adecuado para ambas instancias de poder, situó a los Fernández Heredia en una escalada progresiva de ascenso, tanto en el orden institucional como en el medio social. El peso de su jurisdicción puede apreciarse en los enfrentamientos con la pequeña nobleza altoaragonesa en familias como los Bardají, Abarca, Mur, Latrás, o Aragües, y los concejos periféricos de su espacio limítrofe. Lo que nos indica su activa presencia en estas zonas y la carga potestativa concedida al puesto, que con el tiempo adquirió relevancia no sólo ante la administración real sino ante la propia nobleza menor y titulada del territorio. Por el Real Privilegio del 30 de octubre de 1599 Felipe II concedía al hijo de don Jerónimo, don Juan Fernández de Heredia, como futuro sucesor del cargo de Justicia de Jaca y de las montañas de Aragón, junto a los dos castillos de alcaldías que regentaba su padre ${ }^{22}$. Hecho que se materializó al ascender don Jerónimo al oficio de Gobernador de Aragón en $1601^{23}$. La dicha magistratura quedó así consolidada con carácter vitalicio y hereditario, como comprobaremos a continuación.

El Privilegio Real otorgado en Valladolid el 20 de agosto de 1591 concedió a don Jerónimo el nombramiento de regente de la General gobernación de Aragón. Con este nuevo ascenso al servicio real, ratificado con el juramento correspondiente en Zaragoza, se consolidaba el futuro del propio don Jerónimo y de los descendientes familiares y colaterales. El linaje trasladaba su área de acción y su residencia, entrando a formar parte de la élite institucional de la capital del Reino, e iniciaba el deseado salto del señorío local a la nobleza regional. Además la experiencia adquirida como justicia de Jaca y de las montañas le había habilitado pródigamente para el desarrollo del nuevo empleo. Sus variados conocimientos le hicieron constatar la importancia defensiva del Pirineo y el estado de sus defensas, 
así como la problemática de la delincuencia existente y tomar medidas para su contención.

La muerte de don Jerónimo acaecida en 1608, promocionó inmediatamente a Don Juan Fernández de Heredia, quien pasó de ejercer la mencionada magistratura de justicia de Jaca y de las montañas de Aragón al cargo de regente de la General gobernación. Para ello recibió primeramente la condición de caballero mesnadero, por nombramiento efectuado en San Lorenzo de El Escorial el 10 de abril de 1608, condición indispensable según los Fueros de Aragón. Permaneció escasamente a cargo de esta magistratura, ya que al poco tiempo, se estableció en Zaragoza, siguiendo la senda paterna. La progresión ascendente de la familia siguió consolidándose con el nombramiento de don Juan como regente de la General gobernación de Aragón, empleo que desempeñó siguiendo la senda trayectoria paterna entre 1608 y 1627, durante la mayor parte del reinado de Felipe III. Obtuvo también la mención de Gentilhombre de boca.

Una vez más los gratos servicios de esta familia a la monarquía se materializaron con la continuación en el cargo del hijo de don Juan Fernández de Heredia, don Pedro Pablo Fernández de Heredia y Zapata, quinto Gobernador del reino desde Don Juan de Urrea, persona ilustre que detentó el puesto en los últimos años del emperador Carlos y gran parte de su sucesor.

\subsection{El precio del honor. La toma de los hábitos de las Or- denes Militares}

Uno de los caminos para obtener el reconocimiento de los servicios prestados a la monarquía era la obtención de un hábito de las Ordenes Militares. A esta consolidada vía accedían muchos personajes del gobierno y de la administración, que la Corona quería premiar, ya fuese por los servicios prestados por uno o varios de los miembros de su clan, o en otro orden de cosas, para conceder mercedes pendientes, y obtener recursos económicos en momentos de necesidades perentorias. Sin lugar a dudas ello permitía conseguir el tan ansiado ascenso de quienes aspiraban a enaltecer su persona y su familia aprovechando la situación favorable de la generosidad real y el interés familiar.

Como ya es sabido, y plenamente demostrado, cuatro eran los grados de limpieza que todo candidato debía de demostrar. Además de la limpieza de sangre y nobleza, se unía la legitimidad y la carencia de oficio manual. Todos estas circunstancias eran patentes en las tres generaciones segundas de la familia de los Fernández de Heredia y a ello se dirigieron los primogénitos de los Fernández de Heredia, don Juan y Don Pedro Pablo. Como caballeros provenientes de las élites de poder de la capital del 
Árbol 3: de los Fernández de Heredia y Péez de Sayas

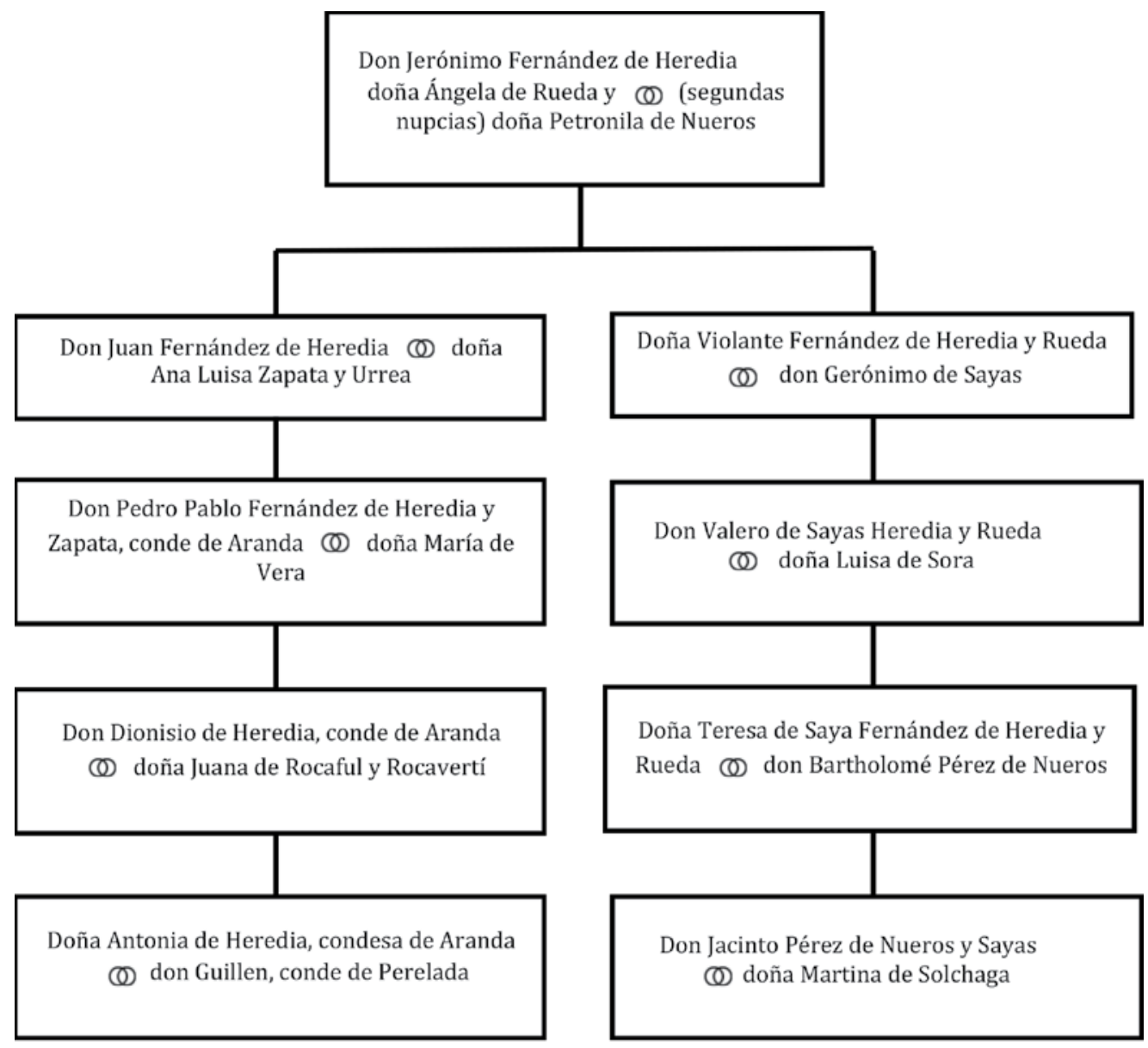


reino, sumaban a ello su pertenencia a la administración del reino y con anterioridad a la magistratura municipal, como un linaje de un palpable camino progresivo y continuado, dedicado a la magistratura real territorial y municipal, luego del reino. Como grupo social contaban con las condiciones necesarias de distinción de las élites sociales que habían superado el primer escalafón nobiliario, eran caballeros, y como otros, necesitaban un nuevo empuje que acelerase su ascenso social.

Don Juan Fernández de Heredia fue nombrado caballero profeso de la Orden de caballería de Santiago, el 7 de agosto de 1593. Posteriormente fue armado caballero el 19 de octubre de 1593 en la Iglesia Catedral de la ciudad de Huesca, siguiendo la Real Provisión del rey Felipe II. Como exigía la Orden deseaba vivir en la "observancia de la regla y disciplina exigida por devoción al bienaventurado Apóstol Santiago", y, como era habitual, se le exigía estar navegando en galeras seis meses cumplidos y posteriormente residir en el convento de la Orden en Vélez durante un año, obedeciendo las reglas de la orden. El ejercicio de ello fue ratificado posteriormente, dando por terminado el exigido cumplimiento con un testimonio de Prior del convento. Nos ha interesado conocer quiénes fueron los padrinos que le acompañaron y, como era la tradición inmemorial, le calzaron las espuelas. Se trataba de don Martín de Bolea Castro y de don Juan Bolea Castro, dos distinguidos miembros de la nobleza y de las élites aragonesas.

Según exigían los Fueros de Aragón don Juan Fernández de Heredia debía prescindir del hábito de caballero de la Orden de Santiago al entrar en la posesión del cargo de Gobernador de Aragón. En consecuencia solicitó la Real licencia para abandonar temporalmente dicha distinción mientras durase el mencionado encargo en el Reino. La Real Cédula del 25 de mayo de 1608, tras el visto bueno del Consejo de Órdenes, le permitió la dejación del hábito sin incurrir en las penas correspondientes ${ }^{24}$.

Tiempo después Don Pedro Pablo Fernández de Heredia recibía también el mencionado hábito de caballería de la Orden de Santiago, que abandonó temporalmente como su padre, al ser nombrado igualmente regente de la General gobernación de Aragón. Este era el precio del honor que exigía el ordenamiento foral aragonés y que era observado con la estimación de la propia tradición consuetudinaria, reiterativamente aplicada. 
La historia volvía a repetirse en un linaje dispuesto a conseguir su merecido ascenso, con un paradigmático modelo, tan creativo como usual, para el reino y para la monarquía de los Austrias.

\section{El acceso al condado de Aranda. La culminación del éxito del linaje}

La vida habría de llevar a don Pablo a realizar altos cometidos y engrandecer a la familia con un brillante futuro en el reino, entre la nobleza titulada y las ocho grandes Casas de Aragón. Nacido en Sisamon, como su padre, en 1602. Fue bautizado el día 6 de julio de 1615 en el templo de Nuestra Señora del Pilar de Zaragoza con el nombre de Don Juan Manuel Jerónimo Antonio Giusepe Buena Ventura Pedro Pablo, asistiéndole como padrinos Blas Rodríguez de Vega y Francisca Velasco.

Este niño ocuparía después, tras la muerte de su padre, la Gobernación de Aragón. En las Cortes de Aragón de 1626 a petición del reino fue acordada la merced de la concesión de la futura sucesión en el oficio de su padre, por concurrir en su persona las cualidades necesarias y la aprobación del Consejo de Aragón. Posteriormente ostentó el encargo de Virrey y lugarteniente general del reino, durante un breve periodo de tiempo, de escasamente un año entre 1668 y 1669. Tras su salida de Aragón acusado de conspirar y atentar contra la vida don Juan José de Austria, nombrado entonces el príncipe de sangre real Vicario General de la Corona de Aragón y Virrey de Aragón en julio de 1669. Don Pedro Pablo ocupó entonces el encargo de Capitán General de Galicia entre 1673 y 1677, del que fue depuesto a instancia de don Juan José de Austria, primer ministro entonces de la Monarquía.

Por la línea interrumpida de la sucesión familiar de la casa de Aranda, recayó en su persona el importante legado de esta familia, tras el fallecimiento del conde don Antonio Xímenez de Urrea Alagón y Espes, conde de Aranda y de Sastago, en 1654. Tras establecer que el testamento era nulo y no ser admitidos los recursos de su viuda doña Felipa Clavero, a quien había nombrado heredera universal, y quien reclamaba el legado del conde los estados de Aranda en Aragón y en Valencia, los estados del condado de Sastago y todas las baronías agregadas a dicho estado, parte de ello pasó a este miembro de la familia de los Fernández Heredia. Trascurridos los polémicos e interesantes pleitos, dónde los fueros y contrafueros fueron objeto de arduos debates tanto en la Audiencia de Aragón como en la Corte del Justicia de Aragón, don Pedro Pablo consolidó su título. La Audiencia de Aragón declaró nulo el testamento por sentencia del 23 de marzo de 1667. Era entonces ya VI conde de Aranda de Moncayo, Vizconde de Biota, señor de Vilueña y de Valtorres. Este legado y el de los Fernández 
de Heredia pasaron luego a su hijo, consolidando la línea sucesoria del heredado nuevo linaje. Murió en Épila en $1681^{25}$.

Don Dionísio Ximénez de Urrea Zapata Fernández de Heredia, incrementó todavía más la preeminencia de esta nobleza titulada con más títulos y posesiones en diversos lugares de la monarquía española. No había concluido todavía el siglo XVII.

La transmisión de los títulos y patrimonio territoriales de este vetusto grupo nobiliario a finales del siglo XVII, era el resultado de un linaje transformado que desde el apellido de los Díez de Aux, dio paso al linaje de los Fernández de Heredia, para concluir en la descendencia directa del condado de Aranda. El triunfo social, la preeminencia histórica y el apoyo de la Corona a lo largo del tiempo, estableció definitivamente el triunfo de una Casa de carácter regional, inmersa definitivamente en el río de la inmemorial Casa de Aranda, que llegaría a ser una de las más grandes de la monarquía.

\section{Conclusión}

La familia y parentela de los Fernández Heredia se había convertido a mediados del siglo XVII en un ejemplo de ascenso social utilizando todas las vías adecuadas en el momento. Entroncados hábilmente con distintas familias situadas en la espiral ascendente desde los siglos $\mathrm{XV}$ y XVI, sus matrimonios y enlaces colaterales les había proporcionado una innegable posición social. La fortuna y los señoríos añadidos al primitivo tronco originario constituyeron, a todas luces, un ejemplo de prosperidad, crecimiento económico y consolidación social. El progresivo ascenso nobiliario se había desarrollado con un camino impecable, de señores de vasallos a nobleza titulada para conseguir la entrada del linaje entre las grandes Casas nobiliarias de la grandeza del reino y posteriormente de la monarquía de los Austrias y de los Borbones.

El linaje de los Fernández de Heredia ha constituido, a mi humilde entender, un modelo histórico paradigmático de los variados caminos de encumbramiento de la nobleza aragonesa, y al fin y al cabo de la nobleza de la monarquía peninsular en el Antiguo Régimen.

25 Ponencia presentada en el congreso War and Society in the Spanish Monarchy: Politics, Strategy and Culture in Early Modern Europe (1500-1700) celebrado en Madrid los días 12 y 13 de marzo de 2015, con el título: Dos visiones políticas y militares en el antemural de Francia: El VI conde de Aranda y Juan José de Austria. 


\section{Bibliografía}

Bermejo Cabrero, J. L. (1985): "Sobre noblezas, señoríos y mayorazgo". Anuario de historia del derecho español, 55, Ministerio de Justicia y Boletín Oficial del Estado, Madrid, pp. 253-306.

Burgos Esteban, F. M. (1994): Los lazos del poder. Obligaciones y parentesco en una élite local castellana en los siglos XVI y XVII. Universidad de Valladolid, Secretariado de Publicaciones, Valladolid.

ColÁs Latorre, G. y Salas Auséns, J. A. (1982): Aragón en el siglo xVI: alteraciones sociales y conflictos políticos. Universidad de Zaragoza, Zaragoza.

Delgado Barrado, J. M. y López Arandia, M. A. (2009): Poderosos y privilegiados. Los Caballeros de Santiago de Jaén (Siglos XVI-XVIII). Consejo Superior de Investigaciones Científicas, CSIC, Madrid.

Desportes Bielsa, P. (1998): "El justicia de las montañas". Serrablo, 108, Amigos del Serrablo, pp. 21-24.

GASCÓN PÉREZ, J. (2001): La rebelión aragonesa de 1591 [Recurso electrónico]. Universidad de Zaragoza, Zaragoza.

GIMÉnez Soler, A. (1899): "El Justicia de Aragón, Martín Díez de Aux" (http://www.derechoaragones.es/i18n/catalogo_imagenes/grupo.cmd? path=101364). Revista de archivos, bibliotecas y museos, tomo 3, Madrid, pp. 385-391.

Gómez de Valenzuela, M. (2000): Estatutos y Actos Municipales de Jaca y sus Montañas (1417-1698). Fuentes Históricas Aragonesas, $n^{\circ}$ 33. Institución Fernando el Católico, Zaragoza.

- (2006a): Diplomatario tensino (1315-1700). Real Sociedad Económica de Amigos del País, Zaragoza.

- (2006b): La vida en el valle de Tena en el siglo XVIII. Instituto de Estudios Altoaragoneses y Ayuntamiento de Sallent de Gállego, Huesca.

Gómez GonzÁlez, I. y López-Guadalupe Muñoz, M. L. (eds.) (2007): La movilidad social en la España del Antiguo Régimen. Comares, Granada.

Gómez Zorraquino, J. I. (2008): "El justicia de las montañas de Aragón (1585-1672): La institución y sus oficiales". Revista de Historia Moderna, Anales de la Universidad de Alicante, 26, Marcial Pons, Madrid, pp. 61-89. Leonardo de Argensola, B. (1995): Alteraciones populares de Zaragoza. Año 1591. Institución Fernando el Católico, Zaragoza.

Mascareñas, J. (1661): Definiciones de la Orden de caballería de Calatrava conforme al Capítulo celebrado en Madrid. Madrid. 
Molas I Ribalta, P. (1993-1994): "La administración real en la Corona de Aragón". Chronica nova: revista de historia moderna de la Universidad de Granada, 21, Universidad de Granada, Granada, pp. 427-440.

- (1998): "Letrados y nobles en la Corona de Aragón". En Martínez Millán, J. (dir.): Felipe II (1527-1598) : Europa y la monarquía católica. Congreso Internacional "Felipe II (1598-1998), Europa dividida, la monarquía católica de Felipe II (Universidad Autónoma de Madrid, 20-23 abril 1998), vol. 2, Parteluz, Madrid, pp. 571-584.

Morales Arrizabalaga, J. (2007): Fueros y Libertades del Reino de Aragón. De su formación medieval a la crisis preconstitucional (1076-1800). Rolde de Estudios Aragoneses, Zaragoza.

Postigo Castellanos, E. (1987): Honor y privilegio en la Corona de Castilla: el Consejo de las Órdenes y los Caballeros de Hábito en el s. XVII. Junta de Castilla y León, Valladolid.

Sanz CAmañes, P. (coord.) (2005): La Monarquía Hispánica en tiempos del Quijote. Sílex ediciones, Madrid.

Savall y DrondA, P. y PenÉn DebeSA, S. (1991): Fueros, Observancias y Actos de Corte del Reino de Aragón led. facs. con estudio preliminar de Jesús Delgado Echeverría), tomo I. El Justicia de Aragón e lbercaja, Zaragoza. WRIGHT, L. P. (1982): "Las Órdenes Militares en la sociedad española de los siglos XVI y XVII. La encarnación institucional de una tradición histórica". En EщıOT, J. H. (ed.): Poder y sociedad en la España de los Austrias, Crítica, Barcelona. 